\title{
Cerebral Reactions during Intrauterine Asphyxia in the Sheep. I. Circulation and Oxygen Consumption in the Fetal Brain
}

\author{
I. KJellmer, ${ }^{[23]}$ K. Karlsson, T. Olsson, and K. G. Rosén
}

Department of Pediatrics, the Department of Physiology and the Department of Gynecology and Obstetrics I, University of Göteborg, and the Research Laboratory of Medical Electronics, Chalmers University of Technology, Göteborg, Sweden

Extract

Cerebral blood flow $(\mathrm{CBF})$ with the ${ }^{133} \mathrm{Xe}$ clearance technique and cerebral oxygen consumption were measured in the fetal lamb using chloralose-anesthetized ewes and acutely exteriorized fetuses with intact umbilical circulation. To induce fetal hypoxia at different $\mathrm{pH}$ levels, three different procedures were used: (1) the ewe was ventilated with a hypoxic gas mixture, containing $8-15 \% \mathrm{O}_{2}$ in $\mathrm{N}_{2}$; (2) $5-10 \% \mathrm{CO}_{2}$ was added to the hypoxia gas mixture; (3) during hypoxia a continuous rapid infusion of $\mathrm{NaHCO}_{3}$ solution was given intravenously to the fetus. Blood gas tensions, $\mathrm{pH}$, and oxygen saturation were measured repeatedly.

Multiple regression analysis was carried out on the data with the variables $\mathrm{Sa}_{\mathrm{O}_{2}}$, $\mathrm{Pa}_{\mathrm{O}_{2}}, \mathrm{~Pa}_{\mathrm{CO}_{2}}$, and $\mathrm{pH}$ considered as independent variables and flow as the dependent variable. All complete sets of observations were used amounting to 74 observations in 11 animals. No significant correlation was found between $\mathrm{CBF}$ and $\mathrm{pH}$. $\mathrm{Sa}_{\mathrm{O}_{2}}$ showed the highest correlation to CBF. No further improvement of this correlation was obtained when $\mathrm{Pa}_{\mathrm{CO}_{2}}$ was. added as independent variable. $\mathrm{Pa}_{\mathrm{O}_{2}}$ and $\mathrm{Pa}_{\mathrm{CO}_{2}}$ described jointly the variations of $\mathrm{CBF}$ as well as $\mathrm{Sa}_{\mathrm{O}_{2}}$ alone.

The oxygen consumption of the brain decreased during hypoxia when $\mathrm{Sa}_{\mathrm{O}_{2}}$ was reduced below $40 \%$. The decrease of the metabolic rate for oxygen was a function both of the degree of hypoxia and of $\mathrm{pH}$. When an acidosis was added to the hypoxia a significant reduction of the oxygen consumption of the brain resulted compared with the same degree of hypoxia at normal or only moderately reduced $\mathrm{pH}$ levels.

\section{Speculation}

The cerebral blood flow of the fetal lamb is regulated mainly via the amount of oxygen available to the brain, and changes of $\mathrm{CO}_{2}$ tension affect $\mathrm{CBF}$ via a displacement of the hemoglobin dissociation curve.

Cerebral oxygen consumption is reduced to dangerously low levels when a severe acidosis is combined with hypoxia because of a failure to extract the oxygen available in the arterial blood.

\section{Introduction}

The response of the cerebral vasculature to hypoxia and hypercarbia has been studied extensively in adult animals. The information available from fetuses or newborn animals is sparse. Studies using flow metering in one carotid artery on the fetal and newborn lamb have demonstrated that carotid artery blood flow increases during hypoxia and hypercarbia $[7,9,10]$. 
However, using a semichronic preparation Quilligan et al. [13], were unable to demonstrate any significant increase of carotid blood flow in the lamb fetus during hypercarbia. Using isotope wash-out techniques, Purves and James [12] demonstrated the occurrence of autoregulation and of vasodilatation due to hypoxia in the cerebral circuit. Their estimate of the oxygen consumption of the fetal brain was recently claimed to be an underestimate by Macowski et al. [8]. The latter authors based their calculations on results obtained with the microsphere injection method in a chronic lamb fetus preparation.

The present study was designed to establish the quantitative relation between cerebral blood flow and cerebral oxygen consumption, on the one hand, and the degree of hypoxia, on the other, in the fetal brain. A further goal was to investigate whether this relation is affected by simultaneous changes of $\mathrm{pH}$, i.e., whether an acidosis superimposed on the hypoxia modified the vascular response to the hypoxia or affected the oxygen consumption of the brain.

\section{Methods}

The experiments were conducted on 11 ewes of mixed breed with 12 fetuses. The estimated gestational age ranged from 94 to 145 days (term 145-150 days). The gestational age was estimated from the fetal weight and crown-rump length using standard curves [6].

Food was restricted for $24 \mathrm{hr}$ before the experiment, water provided ad libitum. The anesthesia was induced with pentothal $(5 \%, 0.1 \mathrm{ml} / \mathrm{kg})$ and chloralose (1.4 $\mathrm{ml} / \mathrm{kg}$ ), given intravenously. The chloralose was 25 $\mathrm{mg} / \mathrm{ml}$ in $5 \%$ borax solution.

To avoid hypoglycemia, a slow, continuous intravenous infusion of $10 \%$ glucose solution $(50-100 \mathrm{ml} /$ hr) was given to the ewe throughout the whole experiment. The ewes were tracheotomized and ventilated with known gas mixtures using an open-circuit ventilator, Starling's Ideal animal ventilator [15]. Maternal blood pressure and heart rate were recorded through a catheter placed in the medial plantar artery of one foreleg. This catheter was also used for arterial blood sampling from the mother.

The abdomen of the ewe was opened with a low paramedian incision, the uterus exposed, and its wall stitched to the abdominal wall. The uterus was opened, and the fetus delivered onto a thermoregulated board, heated to maintain a rectal temperature at $39^{\circ} \pm 0.5^{\circ}$.

The fetal trachea was cannulated immediately after delivery. To avoid fetal breathing this cannula was connected to a water-filled bag.
The fetus was heparinized with 1,000 IU of heparin. Fetal blood pressure and heart rate were recorded through a polyethylene catheter in the right bracheal artery with a Statham P23 AC-pressure transducer [16]. Arterial blood samples were taken from the same catheter. A polyethylene catheter, PE50, was placed in arteria lingualis or arteria thyreoidea superior in a retrograde direction with the tip of the catheter just inside the common carotid artery. Blood samples representative of cerebral venous blood were taken from the superior sagittal sinus through an indwelling scalp vein needle, cemented to the scalp with tissue adhesive.

Through the catheter in the common carotid artery $50-150 \mu \mathrm{Ci}{ }^{133} \mathrm{Xe}$ in $0.5 \mathrm{ml}$ saline was injected as a bolus for each determination of cerebral blood flow [17]. The exponential decay of the activity was measured for $20 \mathrm{~min}$ with a 2 -inch thallium-activated scintillation detector through a collimator, $2 \mathrm{~cm}$ in diameter, placed over the side of the injection. The collimator was placed at the midpoint between the external auditory meatus and sagittal sinus of the fetal head. An additional lead shield reduced the radiation from other parts of the preparation. The counter was connected to a rate meter with a variable time constant, Philips PW4242 [18]. A time constant of $1 \mathrm{~s}$ was used for the first $4 \mathrm{~min}$ of the decay curve, and one of $4 \mathrm{~s}$ for the remainder. The rate meter output was recorded on a linear potentiometer ink recorder [19] with a maximal amplitude of $20 \mathrm{~cm}$. The expired air from the ewe was led outside the laboratory to keep the background activity low. The decay curve was plotted semilogarithmically after background subtraction. This curve was analyzed graphically according to the method of Häggendal et al. [2] to give two straight lines, a fast and a slow component. The fast component has been taken to represent blood flow through gray matter $[2,12]$. The slow component has been claimed to represent white matter blood flow, but because of the likelihood of recirculation this phase has been disregarded in the present analysis. Blood flow was calculated using the formula: blood flow $=\lambda \ln 2 / \mathrm{T}_{1 / 2}$ (milliliters/(100 g.min)).

The partition coefficient $\lambda$ was read from the curves presented by Purves and James [12] using the hematocrit, measured at each xenon injection. The same authors tested the significance of the components of the washout curve and demonstrated the similarity between the fast component and the monoexponential decay curve obtained after a microinjection of tracer into the cortical layer. It should be realized, however, that our measurements of "cerebral blood flow" only 
represent flow through an anatomically ill-defined portion of the cerebral cortex and do not represent overall cerebral blood flow.

In some experiments the blood flow through one common carotid artery was measured continuously with an electromagnetic flowmeter [16]. No attempts were made to ligate branches supplying the parts of the head other than the brain. Maternal and fetal arterial blood pressure, fetal heart rate and carotid blood flow were recorded using a Grass model $7 B$ polygraph [20]. The ewes were ventilated with known gas mixtures with $30 \% \mathrm{O}_{2}$ to maintain fetal $\mathrm{Pa}_{\mathrm{O}_{2}}$ and $\mathrm{Pa}_{\mathrm{CO}_{2}}$ within normal limits [5]. To induce fetal hypoxia at different $\mathrm{pH}$ levels, three different procedures were used: the ewe was ventilated with a hypoxic gas mixture, containing $8-15 \% \quad \mathrm{O}_{2}$ in $\mathrm{N}_{2}$, to bring the $\mathrm{Pa}_{\mathrm{O}_{2}}$ of the ewe from $80-120$ to $25-40 \mathrm{~mm} \mathrm{Hg} ; 5-10 \%$ $\mathrm{CO}_{2}$ was added to the hypoxic gas mixture; during hypoxia a continuous, rapid infusion of $1 \mathrm{M} \mathrm{NaHCO}$ solution was given via the jugular vein to the fetus at a rate of $1.1-1.6 \mathrm{ml} /(\mathrm{min} \cdot \mathrm{kg})$. Each period of hypoxia lasted $20 \mathrm{~min}$. The ${ }^{133} \mathrm{Xe}$ was injected $10 \mathrm{~min}$ after starting the hypoxia and blood samples were taken 5 min later.

The ewes were randomly exposed to normoxia, hypoxia, or hypoxia plus $\mathrm{pH}$ changes. Between the different periods of hypoxia, control periods were inserted in which the ewes were ventilated with $30 \% \mathrm{O}_{2}$ in $\mathrm{N}_{2}$ for $30-60 \mathrm{~min}$. Blood gas tensions and $\mathrm{pH}$ were immediately measured at $38^{\circ}$ with a Radiometer pHM27GM [21], using standard $\mathrm{Po}_{2}$ and $\mathrm{PCO}_{2}$ electrodes. Oxygen saturation $\left(\mathrm{So}_{2}\right)$ was measured, using a filter photometer, Radiometer OSM 1 [21]. The oxygen content was calculated from the saturation value and the hemoglobin concentration, on the assumption that $1 \mathrm{~g}$ hemoglobin maximally binds $1.34 \mathrm{ml} \mathrm{O}_{2}$. The oxygen consumption of the brain was calculated from the blood flow measurement and the arteriovenous differ- ence for $\mathrm{O}_{2}$ content. This is not a measure of overall cerebral oxygen consumption but corresponds to the part of the brain represented by the fast components of the clearance curve, provided that this part of the brain drains its venous blood into the sagittal sinus.

\section{Statistical Methods}

Multiple regression analysis was carried out on the data with the variables $\mathrm{So}_{2}, \mathrm{Po}_{2}, \mathrm{PCO}_{2}$, and $\mathrm{pH}$ considered as independent variables and flow as the dependent variable. All complete sets of observations were used, amounting to 74 observations from 11 animals. To decrease variance arising from different intraindividual levels of blood flow or blood gases the analysis was also performed after normalization of the variables. As the reference for each individual the value with $\mathrm{Po}_{2}, \mathrm{PCO}_{2}$, and $\mathrm{pH}$ values within the normal range given by Joelsson et al. [5] was used. In 9 of the 11 fetuses, this corresponded to the first observation performed. Confidence intervals and significances were determined using standard procedures, well described in Snedecor and Cochran [14].

\section{Results}

Blood gases, heart rate, and mean arterial blood pressure for the ewe and the fetus are tabulated in Table I. These are basal values obtained immediately before the first period of hypoxia. Table I also contains information about the cerebral blood flow and cerebral oxygen consumption obtained as basal values in the present series.

The reactions to hypoxia of cephalic blood flow, ${ }^{133} \mathrm{Xe}$ clearance, heart rate, and arterial blood pressure are exemplified in Figures 1 and 2. In a total of 35 periods of hypoxia in 12 different animals, the ${ }^{133} \mathrm{Xe}$ clearance increased on each occasion as compared with the control period. In 16 periods of hypoxia, the

Table I. Basal values for blood gases, hematocrit (Hct), cerebral blood flow (CBF), mean arterial blood pressure (BP), heart rate (FHR), and cerebral oxygen consumption $\left(\mathrm{V}_{2}\right)$ in fetal lamb ${ }^{1}$

\begin{tabular}{|c|c|c|c|c|c|c|c|c|}
\hline Subject & $\mathrm{pHI}$ & $\mathrm{PaO}_{2}, \mathrm{~mm} \mathrm{Hg}$ & $\mathrm{PaCO}_{2}, \mathrm{~mm} \mathrm{Hg}$ & Hct, \% & $\begin{array}{l}\mathrm{CBF}, \mathrm{ml} / \\
(\mathrm{min} \cdot 100 \mathrm{~g})\end{array}$ & $\mathrm{BP}, \mathrm{mm} \mathrm{Hg}$ & FHR, beats/min & $\begin{array}{c}\dot{\forall} \mathrm{O}_{2}, \mathrm{ml} / \\
(\min \cdot 100 \mathrm{~g})\end{array}$ \\
\hline \multicolumn{9}{|l|}{ Ewe (11) } \\
\hline $\bar{\chi}$ & 7.45 & 115 & 35.3 & 28.6 & & 93.8 & & \\
\hline sD & 0.06 & 22.5 & 5.2 & 4.62 & & 19.2 & & \\
\hline Range & $7.35-7.55$ & $80-152$ & $29-48$ & $23-38$ & & $75-140$ & & \\
\hline \multicolumn{9}{|l|}{ Fetus (12) } \\
\hline $\bar{\chi}$ & 7.29 & 28.7 & 43 & 49 & 56.1 & 52 & 162 & 2.04 \\
\hline SD & 0.08 & 3.0 & 4.9 & 5.1 & 13.1 & 10.4 & 29.4 & 0.78 \\
\hline Range & $7.17-7.41$ & $24-33$ & $34-50$ & $40-57$ & $36-80$ & $36-75$ & $114-222$ & $1.3-3.5$ \\
\hline
\end{tabular}

${ }^{1}$ Number of experimental animals is shown in parentheses. 
cephalic blood flow (measured with the electromagnetic flow probe applied to one carotid artery) increased on 15 occasions and stayed unchanged on one occasion. The increase of the cephalic blood flow was not always proportional to the increase of the rate of ${ }^{133} \mathrm{Xe}$ clearance. The electromagnetic flow probe measurements were used to define the time when a steady state had been reached during hypoxia, usually after 5-10 min, and to observe when the hyperemia accompanying hypoxia had faded away, usually after $30-45 \mathrm{~min}$.

The increase of the cerebral blood flow, as measured with the ${ }^{133} \mathrm{Xe}$ clearance rate, was related to the degree of hypoxia as well as to the degree of hypercarbia. Figure 3 demonstrates the relation between the arterial $\mathrm{CO}_{2}$ tension and the cerebral blood flow when the whole material is divided into two groups according to either a normal or a low $\mathrm{Po}_{2}$ in arterial blood. A linear relation between cerebral blood flow and $\mathrm{PCO}_{2}$ at normal oxygen tensions appears to be distorted at low oxygen tensions, when the blood flow has already increased. To test whether such a nonlinear relation be- tween cerebral blood flow and blood gases existed a statistical analysis was undertaken.

Mean values, standard deviations, range, and correlations for the 74 observations on 11 fetuses are given in Tables II and III. The correlations presented are obtained from absolute as well as normalized values. Although high correlations exist between the connected pairs of variables $\mathrm{So}_{2}-\mathrm{Po}_{2}$ and $\mathrm{PCO}_{2}-\mathrm{pH}$, the correlation between either $\mathrm{So}_{2}$ or $\mathrm{PO}_{2}$ with one of $\mathrm{PCO}_{2}$ or $\mathrm{pH}$ is only weak. This demonstrates that the oxygenation of the fetus could be altered independently with regard to acid-base parameters. Because there is no significant correlation between blood flow and $\mathrm{pH}$, the latter variable is disregarded in the further analysis. $\mathrm{SO}_{2}$ shows the highest correlation to blood flow, both when absolute and normalized values are used (Table III). A regression analysis with flow versus $\mathrm{SO}_{2}$ explains more than $50 \%$ of the variance of flow, using normalized variables $\left(\mathrm{R}^{2}=0.56\right)$. No significant improvement is obtained when the other variables $\left(\mathrm{PCO}_{2}\right.$, $\left.\mathrm{PO}_{2}\right)$ are added $\left(\mathrm{R}^{2}=0.58\right)$.

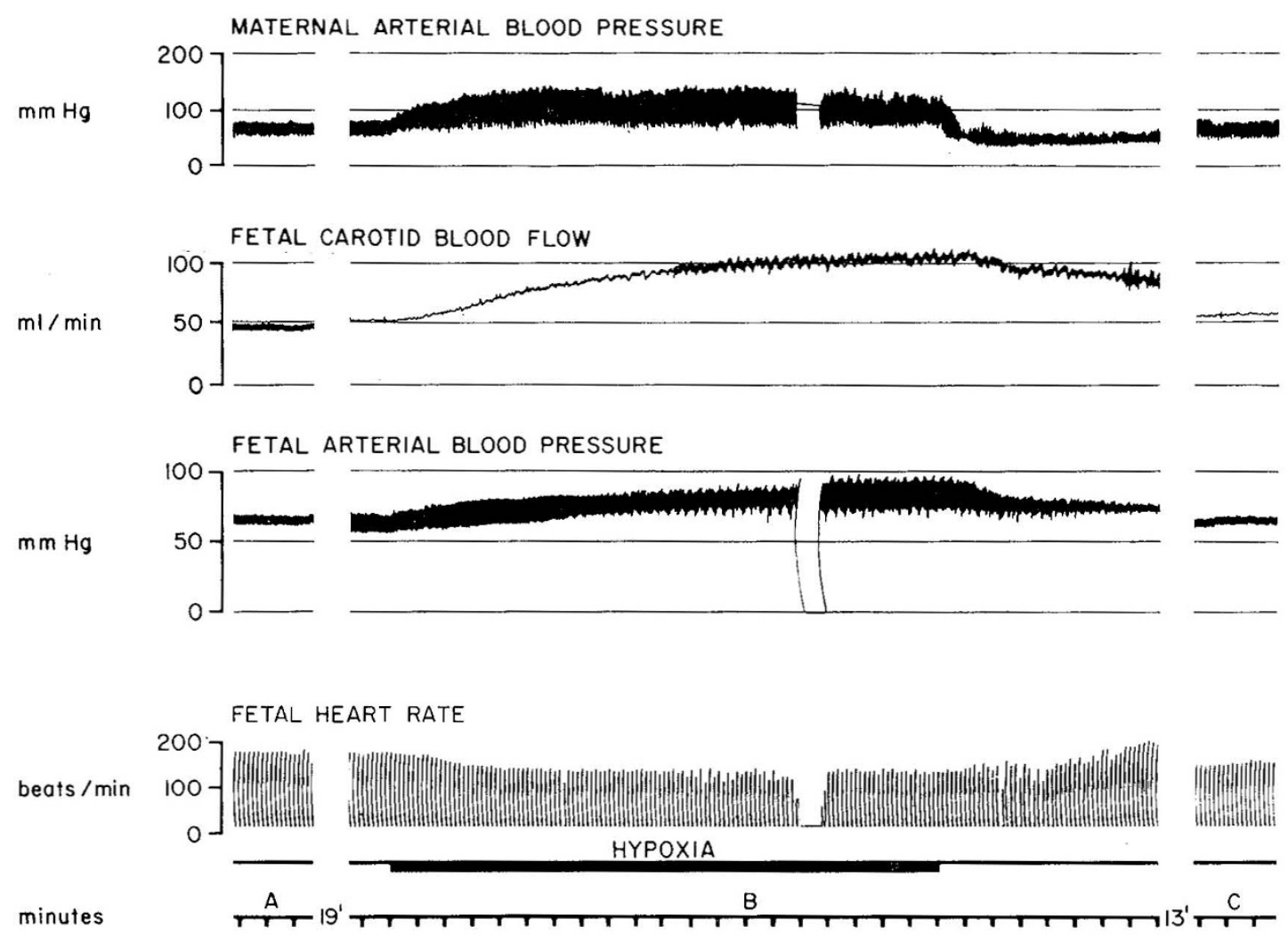

Fig. 1. Example of the reactions of carotid blood flow, arterial blood pressure, and heart rate in the fetus during hypoxia and $\mathrm{CO}_{2}$ retention. Estimated gestational age 142 days. During control periods $\left(A\right.$ and $C$ ) the ewe was ventilated with $30 \% \mathrm{O}_{2}$, during hypoxia $(B) 10 \%$ $\mathrm{O}_{2}, 10 \% \mathrm{CO}_{2}$, and $80 \% \mathrm{~N}_{2} . A, B$, and $C$ correspond to times when ${ }^{133} \mathrm{Xe}$ was injected intra-arterially. The recorded Xe clearance curves are displayed in Figure 2. 


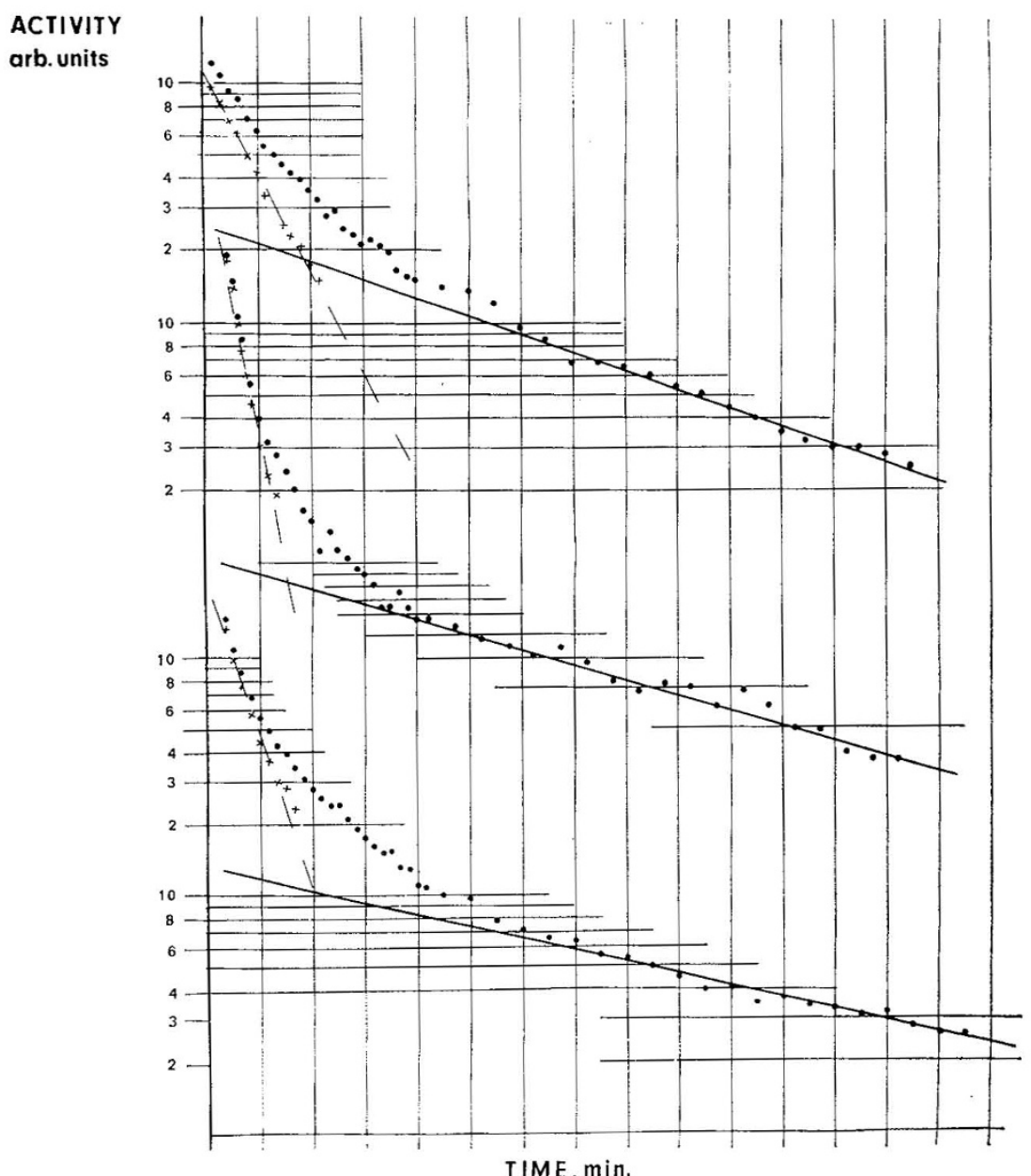

Fig. 2. Semilogarithmic plots of the ${ }^{133} \mathrm{Xe}$ clearance curves obtained from the same experiment as in Figure 1, with curves $A, B$, and $C$ from top to bottom. Peak activity for each curve corresponds to about $300 \mathrm{cpm}$. : recorded values after background subtraction; - - fitted visually to the last part of the curve; + : obtained after subtracting the - - from - . - - : fitted visually to + (the calculated cerebral blood flow values for the test component were $69 \mathrm{ml} /(\mathrm{min} \cdot 100 \mathrm{~g})$ in $A, 190 \mathrm{ml} /(\mathrm{min} \cdot 100 \mathrm{~g})$ in $B, 116 \mathrm{ml} /(\mathrm{min} \cdot 100 \mathrm{~g})$ in $C)$.

If $\mathrm{SO}_{2}$ is left out of the model, about $50 \%$ of the flow variance is again explained by $\mathrm{Po}_{2}$ and $\mathrm{PCO}_{2}$ jointly $\left(\mathrm{R}^{2}=0.48\right)$. Thus, the two models, flow $=\mathrm{a}_{1} \mathrm{So}_{2}+$ $\mathrm{a}_{0}$ and flow $=\mathrm{b}_{1} \mathrm{Po}_{2}+\mathrm{b}_{2} \mathrm{PCO}_{2}+\mathrm{b}_{0}$, describe the variation in cerebral blood flow equally well. The confidence limits for the variables obtained in these two models are given in Table IV.

The residual variances in the two models were tested against the magnitude of the flow. A significant correlation was found $(\mathrm{R}=0.66$ and 0.72 , respectively, for models $a$ and $b$ ). This indicates diminishing reliability of the model at high cerebral blood flows. A nonlinear model might thus be a better predictor.

The same type of statistical analysis was carried out using $\mathrm{So}_{2}, \mathrm{Po}_{2}, \mathrm{PCO}_{2}$, and $\mathrm{pH}$ in the sagittal sinus blood as independent variables and $\mathrm{CBF}$ as the de- pendent variable. However, the relations found explained less of the variance of flow than when the corresponding blood gas values in the arterial blood were used.

The oxygen consumption of the brain during basal conditions amounted to $2.0 \mathrm{ml} /(\mathrm{min} \cdot 100 \mathrm{~g})$ ('Table $\mathrm{I})$. During hypoxia the oxygen consumption diminished to a variable extent. This decrease occurred when the arterial oxygen saturation was lowered below $40 \%$. However, the decrease of the metabolic rate was a function both of the degree of hypoxia and of $\mathrm{pH}$ (Fig. 4). From this figure two extreme groups were selected for comparison. Only values of oxygen saturation below $40 \%$ were considered. One group of values, in which the oxygen consumption was only moderately reduced (oxygen consumption above 1.0 

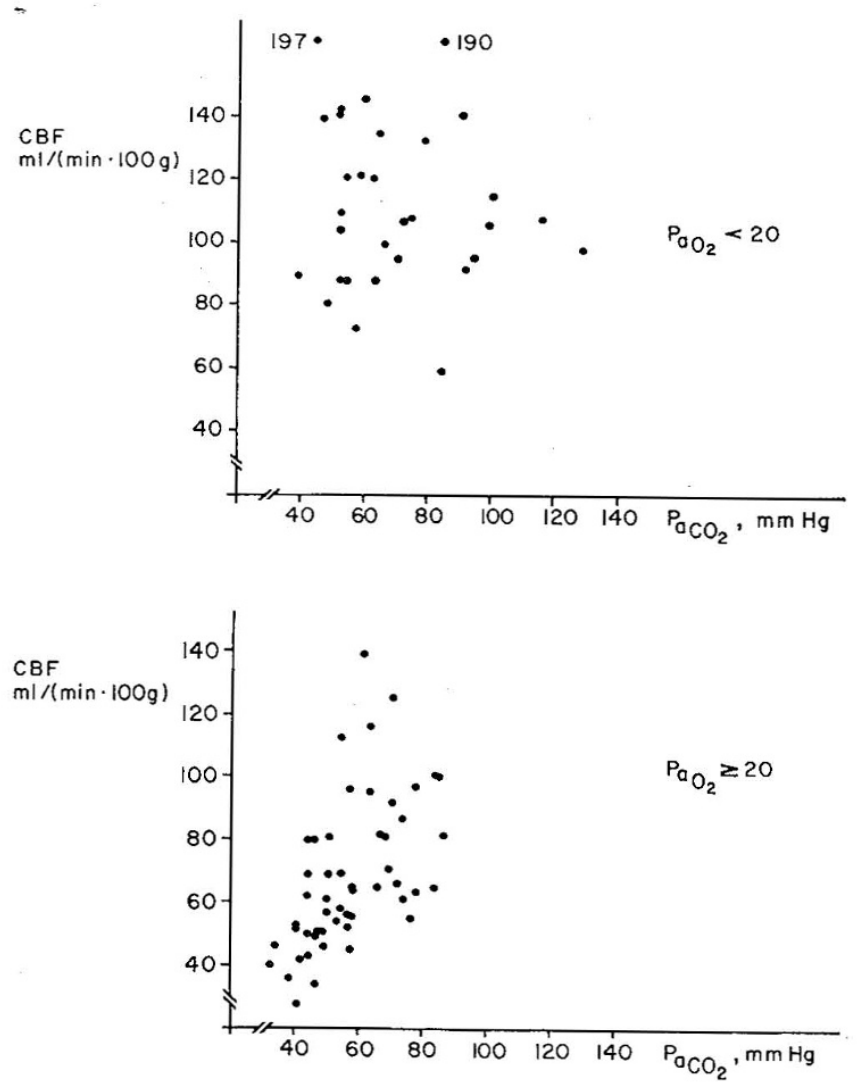

Fig. 3. Graphic correlation between $\mathrm{PCO}_{2}$ and cerebral blood flow (CBF). The upper part of the figure gives values collected during hypoxia $\left(\mathrm{Pa}_{\mathrm{O}_{2}}<20\right)$. The lower part of the figure demonstrates the correlation at a normal $\mathrm{Pa}_{\mathrm{O}_{2}}\left(\mathrm{~Pa}_{\mathrm{O}_{2}} \geqslant 20\right)$.

Table II. Description of variables used for multiple regression analysis

\begin{tabular}{lccc}
\multicolumn{1}{c}{ Variable } & Mean & sD & Range \\
\hline Flow, $\mathrm{ml} /(\mathrm{min} \cdot 100 \mathrm{~g})$ & 84 & 35 & $28-197$ \\
$\mathrm{SO}_{2}, \%$ & 49 & 27 & $28-88$ \\
$\mathrm{Po}_{2}, \mathrm{~mm} \mathrm{Hg}$ & 22 & 7.7 & $9-39$ \\
$\mathrm{PCO}_{2}, \mathrm{~mm} \mathrm{Hg}$ & 62 & 19 & $32-128$ \\
$\mathrm{pH}$ & 7.24 & 0.18 & $6.81-7.71$ \\
\hline
\end{tabular}

Table III. Correlation matrix between absolute (above) and normalized values (below)

\begin{tabular}{lrrrrr}
\cline { 1 - 3 } Variable & \multicolumn{1}{c}{ Flow } & \multicolumn{1}{c}{ So2 } & \multicolumn{1}{c}{$\mathrm{PO}_{2}$} & $\mathrm{PCO}_{2}$ & $\mathrm{pH}$ \\
\hline Flow & 1.00 & & & & \\
$\mathrm{SO}_{2}$ & -0.58 & & & & \\
& -0.75 & 1.00 & & & \\
$\mathrm{Po}_{2}$ & -0.55 & 0.78 & & & \\
& -0.60 & 0.84 & 1.00 & & \\
$\mathrm{PCO}_{2}$ & 0.37 & -0.52 & -0.26 & & \\
& 0.48 & -0.52 & -0.23 & 1.00 & \\
$\mathrm{pH}$ & 0.10 & 0.16 & -0.14 & -0.53 & \multirow{2}{*}{1.00} \\
& -0.12 & 0.15 & -0.20 & -0.56 & \\
\hline
\end{tabular}

$\mathrm{ml} /(\min \cdot 100 \mathrm{~g}))$, was contrasted with the group of values with the most severe reduction (oxygen consumption below $0.5 \mathrm{ml} /(\mathrm{min} \cdot 100 \mathrm{~g}))$. Table $\mathrm{V}$ compares the two groups with respect to oxygen consumption, arterial oxygen saturation, cerebral blood flow, and arterial $\mathrm{pH}$. The difference of $\mathrm{pH}$ between the groups is statistically significant, using the Wilcoxon rank test.

Table $I V$. Variables for two models ${ }^{1}$

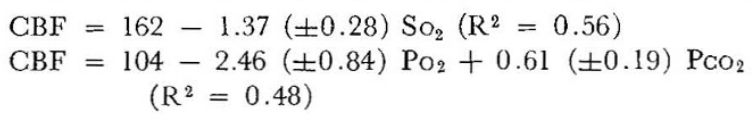

${ }^{1}$ Based on normalized data and transformed to standard variables for convenience by using the mean initial values $\mathrm{So}_{2}=$ $75 \%, \mathrm{PO}_{2}=29 \mathrm{~mm} \mathrm{Hg}$, and $\mathrm{PcO}_{2}=43 \mathrm{~mm} \mathrm{Hg}$. Confidence intervals given are at $5 \%$ level. Cerebral blood flows (CBF) are in milliliters/minute $\cdot 100 \mathrm{~g}, \mathrm{SO}_{2}$ in per cent, and $\mathrm{PO}_{2}$ and $\mathrm{PCO}_{2}$ in $\mathrm{mm} \mathrm{Hg}$.

$$
\dot{\mathrm{V}}_{2}
$$

$$
\mathrm{ml} /(\mathrm{min} \times 100 \mathrm{~g})
$$

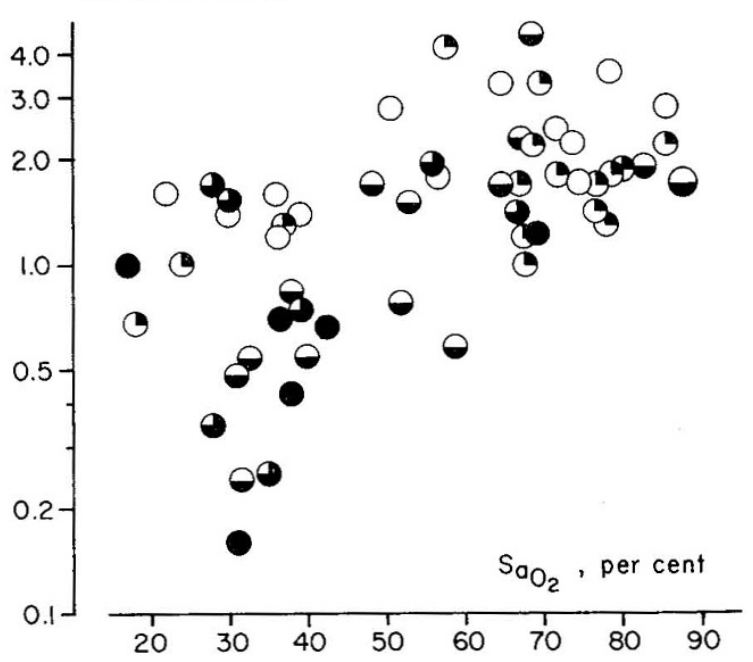

Fig. 4. Graphic correlation between $\mathrm{Sa}_{\mathrm{O}_{2}}$ and the brain oxygen consumption $\left(\dot{\mathrm{V}}_{2}\right)$. The open circles are at a $\mathrm{pH} \geqslant 7.30$; the three-quarter open circles at $\mathrm{pH} 7.20-7.29$; the semifilled circles at $\mathrm{pH} 7.10-7.19$; the three-quarter filled circles at $\mathrm{pH} 7.00-7.09$; and the filled circles at $\mathrm{pH} \leqslant 7.00$.

Table $V$. Comparison between all values in Figure 4 with high group and low group

\begin{tabular}{cccccc}
\hline Group & $\dot{\mathrm{VO}}_{2}$ & $\mathrm{Sa}_{2}$ & $\mathrm{pH}$ & $\mathrm{CBF}^{1}$ & $n$ \\
\hline High group $^{2}$ & 1.50 & 32.3 & 7.39 & 107 & 9 \\
Low group $^{3}$ & 0.32 & 32.5 & 7.02 & 105 & 6 \\
\hline
\end{tabular}

${ }^{1} \mathrm{CBF}$ : cerebral blood flow.

${ }^{2} \mathrm{Sa}_{02}<40 \%$ and $\dot{\mathrm{V}}_{2}>1.0 \mathrm{ml} /(\mathrm{min} \cdot 100 \mathrm{~g})$.

${ }^{3} \mathrm{SaO}_{2}<40 \%$ and $\dot{\mathrm{V}}_{2}<0.5 \mathrm{ml} /(\mathrm{min} \cdot 100 \mathrm{~g})$. 


\section{Discussion}

To compensate for the slight depression of arterial oxygen tensions following anesthesia the ewes were ventilated with $30 \%$ oxygen in air. In this way it was possible to match the blood gas values of the fetuses with those obtained from the chronic lamb fetus preparation [5], although our fetuses had slightly lower $\mathrm{pH}$ levels. This demonstrates that the acute, exteriorized preparation can be maintained at normal conditions in this respect. Our basal values for cerebral blood flow and for cerebral oxygen consumption are about half of those reported by Makowski et al. [8] using the microsphere distribution technique in the intrauterine fetus, but are closely similar to the values given by Purves and James [12], who used the ${ }^{133} \mathrm{Xe}$ clearance method in the acutely exteriorized fetus. Although the blood gas values from the series of Purves and James [12] are virtually the same as our results, Makowski et al. [8] found both a lower mean $\mathrm{Pa}_{\mathrm{O}_{2}}$ value and a higher $\mathrm{Pa}_{\mathrm{CO}_{2}}$ value. Both deviations tend to increase the CBF. The two techniques are, however, not strictly comparable because the microsphere method gives a measure of blood flow representing overall cerebral blood flow including the various parts of the brain while the xenon clearance method measures blood flow in some part of the cortical gray matter.

The significant correlations between $\mathrm{CBF}$ and $\mathrm{S}_{\mathrm{O}_{2}}$, $\mathrm{P}_{\mathrm{O}_{2}}$, and $\mathrm{P}_{\mathrm{CO}_{2}}$ clemonstrated in Table III have been repeatedly found in adult animals and man previously. The lack of correlation between $\mathrm{CBF}$ and changes of $\mathrm{pH}$ when $\mathrm{P}_{\mathrm{CO}_{2}}$ effects are excluded (Table III) was suggested also by Harper and Bell [1] using adult dogs. However, this is a much disputed question and the present results contribute little to this discussion, inasmuch as the $\mathrm{pH}$ and $\mathrm{P}_{\mathrm{CO}_{2}}$ factors are not well separated in this study (Table III).

The findings presented in Figure 3 suggested to us that the correlation between $\mathrm{CBF}$ and $\mathrm{P}_{\mathrm{CO}_{2}}$ might be valid only at normal $\mathrm{P}_{\mathrm{O}_{2}}$ levels and vice versa. The question arose whether cerebral blood vessels that were already dilated by hypoxia could also respond to hypercarbia. Multiple regression analysis demonstrates that the residual variance increases at high $\mathrm{CBF}$ values when investigating the correlation between $\mathrm{CBF}, \mathrm{P}_{\mathrm{O}_{2}}$, and $\mathrm{P}_{\mathrm{CO}_{2}}$. This indicates that the linear model explains a smaller proportion of the CBF changes at high blood flows than at low blood flows.

The mechanism by which $\mathrm{PCO}_{2}$ of the arterial blood exerts its regulating influence on cerebral blood flow is not known, but has been extensively discussed. The most attractive hypothesis at present appears to be an action via a change of the extracellular $\mathrm{pH}$ of the brain. The evidence for this hypothesis was recently reviewed by Purves [11]. The present series of experiments raises another possibility, namely that changes of $\mathrm{PCO}_{2}$ affect $\mathrm{CBF}$ via the displacement of the hemoglobin dissociation curve. From Table IV it is apparent that the changes of $\mathrm{CBF}$ can be as well described by $\mathrm{SO}_{2}$ alone as by the combination of $\mathrm{Po}_{2}$ and $\mathrm{PCO}_{2}$. Further, the addition of $\mathrm{PCO}_{2}$ to the $\mathrm{So}_{2}$ model does not increase the predictive power of this model.

These results suggest the possibility that fetal CBF is regulated by the oxygen saturation of the arterial blood. In the dog a relation between diminished oxygen capacity and raised CBF has already been documented [3].

With either model only little more than half of the CBF variations found are explained by the blood gases (Table IV). A number of other variables might be discussed. Among them are the maturity of the fetus and the neurogenic reflex activity. In experiments using the carotid blood flow method Mann [9] produced evidence to show that cephalic blood flow under basal conditions is unaffected by fetal maturity when expressed per gram of brain tissue. It is conceivable that autonomic nervous tone and reflex activity contribute markedly to the residual variance, as it is well documented, both in the baboon [4] and the fetal lamb [12], that the vascular response of the brain to alterations of blood gases is greatly modified by such circumstances.

A decrease of cephalic oxygen consumption during severe hypoxia in the fetus was described by Mann [10]. Using more moderate degrees of hypoxia, Purves and James [12] obtained no change of the metabolic rate of oxygen in four fetuses. The present results (Fig. 4) indicate a decrease of the oxygen consumption when the oxygen saturation of arterial blood is lowered below $40 \%$. The magnitude of the reduction of oxygen consumption is a function of $\mathrm{pH}$, so that the combination of hypoxia and acidosis produces a more marked inhibition of oxidative metabolism in the brain than hypoxia alone (Fig. 4, Table V). Because acidosis does not affect the total blood flow to the brain (Table V), the drastic reduction of oxygen consumption when hypoxia is combined with acidosis could be caused by two mechanisms: a reduced oxygen extraction from the blood because of a primary effect on the brain cells, or a reduced oxygen extraction because of an unequal distribution of blood flow within the tissue, i.e., a disturbed microcirculation during the combination of hypoxia and acidosis. 


\section{Summary}

Cerebral blood flow (CBF) and cerebral oxygen consumption were measured with the ${ }^{133} \mathrm{Xe}$ clearance method and blood gas analyses in 12 fetal lambs, of 94-145 days of gestational age. Periods of hypoxia were created by ventilating the ewe with appropriate gas mixtures. The $\mathrm{pH}$ of fetal blood was altered via addition of $\mathrm{CO}_{2}$ gas to the ewe, or infusions of alkali to the fetus. Multiple regression analysis of $\mathrm{CBF}$ on blood gases demonstrated no correlation between $\mathrm{CBF}$ and $\mathrm{pH}$, but a significant correlation between $\mathrm{CBF}$ and $\mathrm{Pa}_{\mathrm{O}_{2}}, \mathrm{~Pa}_{\mathrm{CO}_{2}}$, and $\mathrm{Sa}_{\mathrm{O}_{2}}$. The parameter $\mathrm{Sa}_{\mathrm{O}_{2}}$ alone gave the same correlation to $\mathrm{CBF}$ as $\mathrm{Pa}_{\mathrm{O}_{2}}$ and $\mathrm{Pa}_{\mathrm{CO}_{2}}$ in combination. It is suggested that $\mathrm{Pa}_{\mathrm{CO}_{2}}$ influences the $\mathrm{CBF}$ of the fetus via a shift of the hemoglobin dissociation curve.

The oxygen consumption of the brain decreased during hypoxia. The decrease was significantly more profound when the hypoxia was combined with acidosis. Because cerebral blood flow in hypoxia was not, however, diminished in the presence of acidosis, it is suggested that acidosis reinforces the principal ill effects of hypoxia, reduced oxygen consumption in the brain, by a mechanism which curtails the ability of the brain to extract the oxygen made available to it.

\section{References and Notes}

1. Harper, A. M., And Bell, R. A.: The effect of metabolic acidosis and alkalosis on the blood flow through the cerebral cortex. J. Neurol. Neurosurg. Psychiat., 26: 34I (1963).

2. HÄggendal, E., Nilsson, N. J., AND Norbäck, B.: On the components of $\mathrm{Kr}^{85}$ clearance curves from the brain of the dog. Acta Physiol. Scand. Suppl., 258: 5 (1965).

3. Häggendal, E., Nilsson, N. J., ANd Norbäck, B.: Effect of blood corpuscle concentration on cerebral blood flow. Acta Chir. Scand. Suppl., 364: 3 (1966).

4. James, J. M., Millar, R. A., And Purves, M. J.: Observations on the extrinsic neural control of cerebral blood flow in the baboon. Circ. Res., 25: 77 (1969).
5. Joelsson, I., Barton, M. D., Daniel, S., James, L. S., And ADamsons, K.: A method for prolonged monitoring of physiologic functions during fetal life. Amer. J. Obstet. Gynecol., 107: 445 (1970).

6. Joubert, D. M.: A study of pre-natal growth and development in the sheep. J. Agr. Sci., 47: 382 (1956).

7. Lugas, W., Kirschbaum, T., and Assali, N. S.: Cephalic circulation and oxygen consumption before and after birth. Amer. J. Physiol., 210: 287 (1966).

8. Makowski, E. L., Schneider, J. M., Tsoulos, N. G., Colwill, J. R., Batraglia, F. C., And Meschia, G.: Cerebral blood flow, oxygen consumption, and glucose utilization of fetal Iambs in utero. Amer. J. Obstet. Gynecol., 114: 292 (1972).

9. MANN, L. I.: Developmental aspects and the effect of carbon dioxide tension on fetal cephalic blood flow. Exp. Neurol., 26: 136 (1970).

10. MANn, L. I.: Effect of hypoxia on fetal cephalic blood flow, cephalic metabolism, and the electroencephalogram. Exp. Neurol., 29: 336 (1970).

11. Purves, M. J.: The physiology of the cerebral circulation. Monographs of the Physiological Society (Cambridge University Press, 1972).

12. Purves, M. J., ANd James, I. M.: Observations on the control of cerebral blood flow in the sheep fetus and newborn lamb. Circ. Res., 25: 651 (1969).

13. Quilligan, E. J., Dunnihoo, D. R., And Anderson, G. G.: Effect of elevations of carbon dioxide on fetal carotid blood flow. Amer. J. Obstet. Gynecol., 109: 706 (1971).

14. Snedecor, G. W., and Cochran, W. G.: Statistical Methods, Ed. 6 (Iowa State University Press, Ames, Iowa, 1967).

15. Palmer, Ltd., Effra Rd., London SW2, England.

16. Microflo, Statham Instruments, Inc., Oxnard, Calif.

17. AB Atomenergi, Studsvik, Sweden.

18. Philips Electronic Instruments, Mt. Vernon. N. Y.

19. Servogor, Goerz Elektro, RE 520, Austria.

20. Grass Instrument Co., Quincy, Mass.

21. Radiometer Electronik Measuring Instruments, 72 Endrupve; Copenhagen, Denmark.

22. This research was supported by Swedish National Research Council, Grant no. 19X-2591, National Association against Heart and Lung Disease, Förstamajblomman, Swedish Board for Technical Development.

23. Requests for reprints should be addressed to: I. KJELLMER, M.D., Department of Pcdiatrics, Östra sjukhuset, Göteborg, Sweden.

24. Accepted for publication September 15, 1973. 